who are probing new avenues to facilitate their task of leading students into the challenges of the new world more appropriately.

\section{R. Bodenstein}

Department of German

University of Stellenbosch

7600 Stellenbosch

Republic of South Africa

\section{S.D. Krashen \& T.D. Terrell}

The Natural Approach: Language acquisition in the classroom. Oxford: Pergamon, 1983. (Paperback, 191 pp.)

Stated simply, this book is based on the theory that language acquisition occurs when messages are understood. The objective of beginners' classes is to supply much input and by so doing, bring the learner to the point where he/she can understand language outside the classroom. In The Natural Approach: Language Acquisition in the Classroom, Krashen and Terrell attempt to put into practice their theoretical ideas on second language acquisition. It is based on an empirically grounded theory of second language acquisition, which is supported by a large number of scientific studies in a wide variety of language acquisition and learning contexts (p. 1).

Krashen and Terrell state two purposes for their work: to offer an introduction to the Monitor Theory and to provide a handbook for instructors who wish to use a communicative based approach in the classroom. This work offers practical applications of the model for foreign and second language teaching.

The first part of the book gives an overview of Krashen's theory. For those unfamiliar with Krashen's theory, this summary achieves its purpose i.e. to introduce the reader to the Monitor Theory. A background to what is termed "Traditional and Non-Traditional Approaches" to Language Teaching is included.
The latter part of the book is devoted to practical considerations for using the Natural Approach. This includes ways of organizing the syllabus and managing the classroom. Included also are valuable techniques to develop listening and speaking skills as well as the roles of reading, writing, grammar, error correction and testing.

In line with Krashen's Input Hypothesis that language acquisition can only take place when a message which is being transmitted is understood, many of the activities emphasize listening comprehension without extensive speaking. The emphasis is on what is being said rather than on the form of the message.

Krashen and Terrell do not believe that acquisition is affected by conscious learning or productive practice. Teachers are advised therefore that learning exercises such as drills or other controlled practice are not necessary for developing communication skills (p. 148). This implies therefore that teachers should abandon traditional techniques and concentrate on exercises which provide more input. Exercises in this book are most valuable and diversified.

This book is written very clearly and to the point. It is interspersed with various examples to help the teacher understand. This work will serve as resource material to both beginners and experienced instructors.

In The Natural Approach: Language acquisition in the classroom, the joint effort of Krashen and Terrell has made it possible for theory (i.e. Krashen's) and practice (i.e. Terrell's Natural Approach) to interact. The authors provide a practical formulation of the theory. They have adapted it to a variety of situations for different types of learners.

\section{D.S. Gxilishe}

Institute for Language Teaching

University of. Stellenbosch

7600 Stellenbosch

Republic of South Africa 